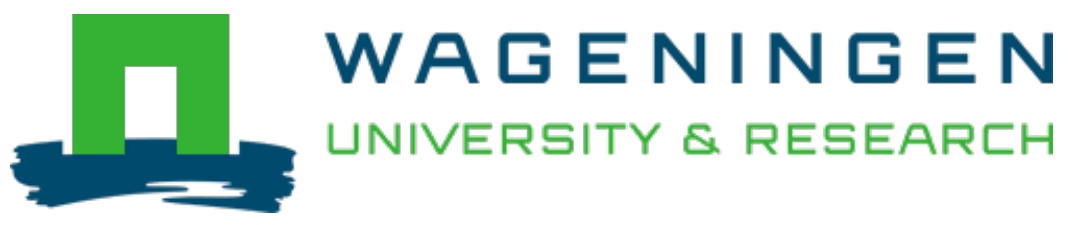

\title{
Nematodes as Drivers of Plant Performance in Natural Systems
}

Trends in Plant Science

Wilschut, Rutger A.; Geisen, Stefan

https://doi.org/10.1016/j.tplants.2020.10.006

This article is made publicly available in the institutional repository of Wageningen University and Research, under the terms of article $25 \mathrm{fa}$ of the Dutch Copyright Act, also known as the Amendment Taverne. This has been done with explicit consent by the author.

Article $25 \mathrm{fa}$ states that the author of a short scientific work funded either wholly or partially by Dutch public funds is entitled to make that work publicly available for no consideration following a reasonable period of time after the work was first published, provided that clear reference is made to the source of the first publication of the work.

This publication is distributed under The Association of Universities in the Netherlands (VSNU) 'Article $25 \mathrm{fa}$ implementation' project. In this project research outputs of researchers employed by Dutch Universities that comply with the legal requirements of Article $25 \mathrm{fa}$ of the Dutch Copyright Act are distributed online and free of cost or other barriers in institutional repositories. Research outputs are distributed six months after their first online publication in the original published version and with proper attribution to the source of the original publication.

You are permitted to download and use the publication for personal purposes. All rights remain with the author(s) and / or copyright owner(s) of this work. Any use of the publication or parts of it other than authorised under article $25 \mathrm{fa}$ of the Dutch Copyright act is prohibited. Wageningen University \& Research and the author(s) of this publication shall not be held responsible or liable for any damages resulting from your (re)use of this publication.

For questions regarding the public availability of this article please contact openscience.library@wur.nl 


\section{Trends in Plant Science}

\author{
Rutger A. Wilschut ${ }^{1, \star}$ and Stefan Geisen ${ }^{2, \star}$
}

Nematodes form an important part of soil biodiversity as the most abundant and functionally diverse animals affecting plant performance. Most studies on plantnematode interactions are focused on agriculture, while plant-nematode interactions in nature are less known. Here we highlight that nematodes can contribute to vegetation dynamics through direct negative effects on plants, and indirect positive effects through top-down predation on plant-associated organisms. Global change alters these interactions, of which better understanding is rapidly needed to better predict functional consequences. By expanding the knowledge of plant-nematode interactions in natural systems, an increase in basic understanding of key ecological topics such as plant-soil interactions and plant invasion dynamics will be obtained, while also increasing the insights and potential biotic repertoire to be applicable in sustainable plant management.

\section{The Rhizosphere and Soil Nematodes}

Plants depend on other organisms to optimize their growth. Pollinators safeguard plant reproduction [1], mutualists, such as mycorrhizal fungi, increase plant performance [2], whereas herbivores and pathogens negatively affect plant health [3]. Most of this basic knowledge on interactions of plants with other organisms originates from agricultural food- and feed-producing systems, with a particular focus on aboveground biointeractions. However, the aboveground part represents only half of the plant, with belowground roots being of equal importance for plant growth. As such, belowground interactions of plants with other organisms are of uttermost importance in determining plant performance [4]. This belowground root-associated biodiversity, the rhizobiome (see Glossary), is composed of microbial bacteria, fungi and protists, as well as animals [5]. All of these components include plant mutualists, pathogens, and many taxa that have neutral impacts on plant growth [5]. Nematodes represent a key group of this rhizobiome biodiversity as the most abundant and functionally diverse animals [6].

Nematodes are both taxonomically and functionally diverse, and occupy several key positions in belowground food webs [7]. Nematode communities are mostly composed of taxa that prey on bacteria, but taxa feeding on plant roots can be similarly abundant [6]. In addition, fungivores, omnivores, and predators are major feeding modes of nematodes in the rhizosphere. By far the most studied group of rhizosphere nematodes are root feeders. Many root-feeding nematodes are well-known pests in agricultural systems, such as species of the genera Pratylenchus and Meloidogyne [8]. Their control is difficult and often only possible with harsh physical or chemical measurements that have unwanted side effects against non-target organisms, or with year-long crop rotation measurements [8,9], as fully reliable biological control agents have not yet been found [10]. But nematodes can also be beneficial to plants. Among the key examples that have found their way even into marketed products are entomopathogenic nematodes [11]. Plants can attract these entomopathogens in response to attacks by root-feeding insects, an idea called the 'cry-for-help hypothesis' $[12,13]$. The majority of rhizosphere nematodes are plant-neutral at the first glance. Yet, through feeding interactions of bacterivorous and

\section{Highlights}

The impact of soil nematodes -the most abundant animals on Earth- on plant performance have mostly been studied in agricultural systems and are only partly understood in natural systems.

There is accumulating evidence that nematodes affect natural plant performance by contributing to negative plant-soil feedbacks, altering rhizosphere microbial communities and enhancing nutrient cycling. Molecular methods will further increase this understanding, especially by elucidating species specificity and underlying molecular mechanisms of plant-nematode interactions.

Increased knowledge is needed to understand how changes in nematode community structure, which are imposed by several global change drivers, feed back to plant performance and plant community composition.
${ }^{1}$ Ecology Group, Department of Biology, University of Konstanz, Konstanz, Germany

${ }^{2}$ Department of Nematology, Wageningen University and Research, Wageningen, The Netherlands

${ }^{*}$ Correspondence: rutger.wilschut@uni-konstanz.de (R.A. Wilschut) and stefan.geisen@wur.nl (S. Geisen). 

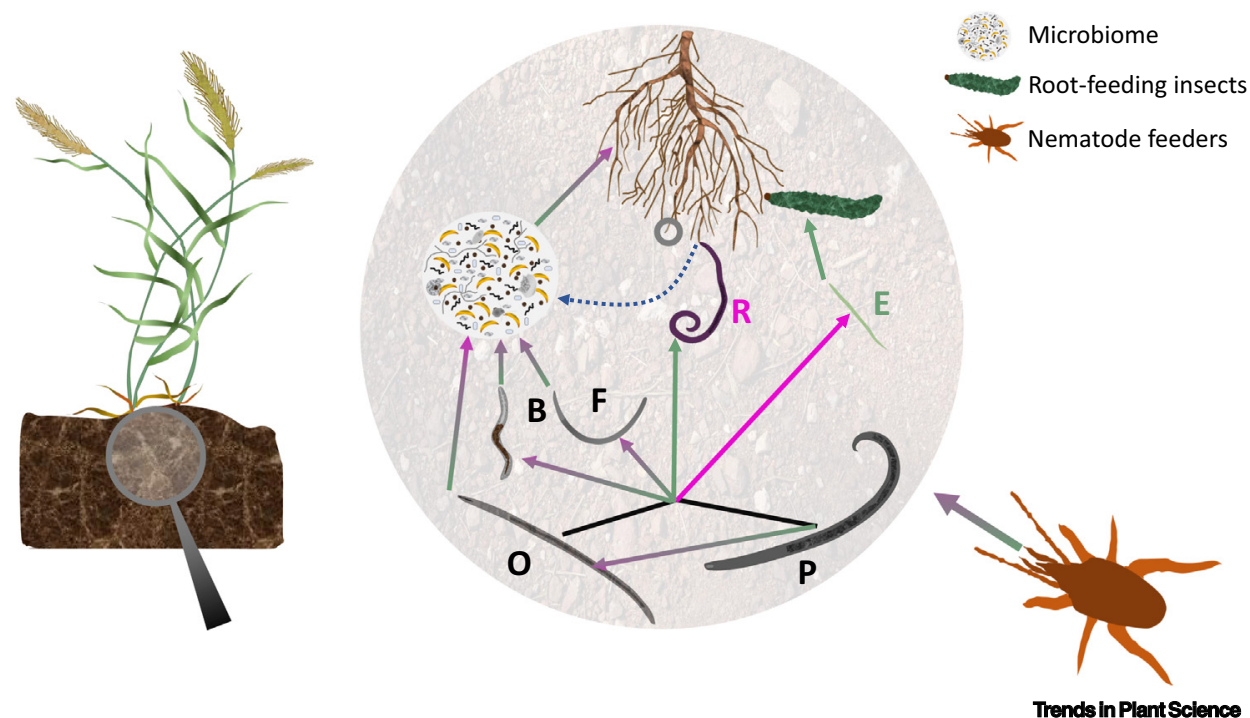

Figure 1. Interactions of Nematode Functional Groups in the Rhizosphere and Their Effects on Plant Growth The rhizosphere nematode community consists of root-feeding nematodes $(R)$, which feed on plant roots. Their usually negative impact (purple letters or arrows) on plant growth can sometimes be positive (green letters or arrows) through plant-mediated changes of the rhizobiome (blue broken line). Bacterivorous (B) and fungivorous nematodes (F) modify the rhizobiome leading to variable effects on plant growth (purple-green arrows). Plants can attract entomopathogenic nematodes (E) to serve as top-down control agents of root-feeding insects. R, B, F, E are exposed to top-down control by omnivorous $(\mathrm{O}$; a group that also directly shapes the rhizobiome) and predatory nematodes $(\mathrm{P})$ that thereby affect plant growth indirectly. Other interactions among nematodes and of nematode-feeding organisms (here illustrated by a mite) are shown that make this nematode-centric food web and the link to plant growth even more complex.

fungivorous taxa, and in the next trophic level, omnivores and predators, these nematodes make nutrients available for plants or provide top-down control on root-feeding nematodes, and can therefore be considered indirectly plant beneficial [14] (Figure 1). Variation in the susceptibility of the enormous taxonomic and functional diversity of nematodes to changes in their surrounding soil has enabled the development of various nematode community metrices, which provide detailed information on soil quality (Box 1) -information that has yet to be translated to inform on the performance of single plant species and the functioning of plant communities.

Here reviewed, is the current knowledge of links between plants and nematodes with a focus on natural systems, with an in-depth discussion of the role of nematodes in plant functioning. Previous reviews have highlighted the differences in nematode communities between agricultural and natural soils, and the role of plants in inducing changes in nematode communities [15-17]. In

\section{Box 1. Nematode Community Indices}

Differences in sensitivity to environmental disturbances between nematode taxa have enabled the development of specific nematode community indices that reflect the state of a soil [104]. Soil disturbance due to, for example, intense agricultural management, is linked to a reduction of higher-trophic level, slow-growing nematode species, and a relative increase in fast-growing bacterivores and fungivores; this change is captured in a reduction of the maturity index and the structure index [56,105,106], or, when soil disturbance is accompanied by increases in nutrients, an increase in the enrichment index [106]. Shifts towards monocultures lead to an enrichment of herbivores relative to other groups (e.g., root feeder-bacterivore ratio), while soil tillage reduces the relative fraction of fungal hyphae and therefore fungivorous nematodes, relative to bacterivores that shifts main decomposition pathways, (e.g., nematode channel ratio) [107]. While developed to study soil health, these metrices are also informative to decipher plant performance in a given soil, and future research should address the question of whether nematode indices can be used to predict the performance of individual plant species.

\section{Glossary}

Biotic homogenization: the increase of similarity between biotic communities, typically due to anthropogenic influences such as land use change, urbanization, and the introduction of non-native plant and animal species.

Ectoparasites: ectoparasitic root-feeding nematodes inhabit the rhizosphere soil and feed from outside the plant root tissue.

Endoparasites: endoparasitic root-feeding nematodes parasitize plants by feeding inside roots, either at multiple sites (migratory endoparasites; e.g., Pratylenchus species), or by manipulating the plant to form a feeding cell where the nematode stays and reproduces (sedentary endoparasites; e.g., Meloidogyne species).

Entomopathogenic nematodes: nematodes that infest soil-dwelling larva stages of aboveground insects, and which are used as biocontrol agents against plant pests.

Holobiont: the concept that a host (e.g., plant) and its associated (micro) organisms together form a

superorganism that functions as one. Metabarcoding: analysis of the diversity and relative abundance of microbial communities, using primers that target molecular markers shared by wide taxonomic groups (e.g., bacteria or fungi). For nematodes, the 18S rRNA gene is targeted.

\section{Nematode community indices:}

indices calculated based on the relative abundance of nematode functional groups (bacterivores, fungivores, etc.) or nematode taxa. Nematode taxa can be assigned to different classes along a colonizer-persister scale, allowing the calculation of, for example, the maturity index, which informs on the disturbance level of a given soil.

Pathotype: a subspecies level classification of root-feeding nematode species based on different pathogenicity levels of plants; equivalent to 'pathovar' in other organisms.

Plant-soil feedback: the manipulation of soil biotic and abiotic conditions by plants, which can negatively or positively affect current and subsequent generations of conspecific and heterospecific plant species. Rhizobiome: the biotic community of the rhizosphere, which consists of microorganisms (bacteria, fungi, protists) and soil animals (nematodes, microarthropods). 
this review, we show how nematodes may contribute to vegetation dynamics by plant speciesspecific accumulation of nematode communities. We differentiate between nematode effects in direct and indirect pathways and indicate how global change drivers might alter these interactions. We stress that there is increasing evidence that climate change factors alter plant-nematode interactions, which potentially has consequences for future vegetation. Finally, we provide views on how methodological advances in plant-nematode research can improve insights into plant-soil interactions, and how knowledge exchange between nematode research fields can help to deepen our understanding of the role of nematodes in plant functioning in both natural and agricultural systems.

\section{Contributions of Root-Feeding Nematodes to Plant-Soil Feedbacks}

Root-feeding nematodes have been studied well in agriculture, but it is still partly unclear how important they are for plant health in natural systems. Root-feeding nematodes are part of the plant species-specific rhizobiome, which plants accumulate through variation in structural and chemical root traits $[18,19]$. This rhizobiome directly determines plant performance but has an arguably even stronger impact on plant growth in subsequent plant generations $[20,21]$. Such plant-soil feedbacks can range from negative to positive, depending on the relative impact of antagonistic and mutualistic soil organisms [21]. Negative plant-soil feedbacks on conspecific individuals contribute to vegetation succession [20,22], grassland dynamics [22], and in agriculture, the need for crop rotation [9]. The accumulation of rootfeeding nematodes by plants is largely determined by plant defense traits, including species-specific root exudates and volatiles, and targeted resistance responses [23-25]. Through variation in such defense traits, plant species may accumulate different numbers of specialist root-feeding nematodes, which have limited host ranges and typically are endoparasites, and generalist root-feeding nematodes, which have wide host ranges and comprise both endoparasites and ectoparasites. Nematode inoculation studies show that high numbers of root-feeding nematodes can negatively affect plant biomass or change plant biomass allocation [26,27], but to what extent root-feeding nematodes affect plant productivity of natural plant communities in the field is not yet fully understood [28,29]. Negative impacts of root-feeding nematodes on plant performance can be partly mitigated by the accumulation of microbes that suppress root-feeding nematodes, an ability that differs between plant species $[30,31]$. While plants can attract microbes using root volatile release [32] just as they can attract entomopathogenic nematodes in response to insect herbivory $[13,33]$, there is no evidence yet that root-feeding nematode attack triggers the attraction of nematode antagonists [34].

In agricultural systems, both specialist (e.g., potato cyst nematodes Globodera) and generalist (e.g., root-knot nematodes Meloidogyne) root-feeding nematodes cause negative plant-soil feedbacks [8] (Figure 2). In natural systems the impacts of root-feeding nematodes on plant performance are less well understood than in agricultural systems [8], and understudied compared with the contributions of other groups of the rhizobiome. Due to their role as plant pests, specialist root-feeding nematodes have been typically identified from agricultural systems, while only few are known from non-crop species (e.g., Heterodera betulae on Betula species) [35]. Molecular studies still reveal a hidden diversity of unknown root-feeding nematodes, even in well-studied agricultural systems [36]. Therefore, it seems likely that specialist root-feeding nematodes, both at the species and strain (i.e., pathotype) level, have been partly overlooked in natural systems, and future molecular studies should point out how common they are. Possibly, specialist root-feeding nematodes are largely confined to ecosystems with highly predictable, low-diversity plant communities [37]. In such communities, for example the wellstudied coastal dune grasslands, specialist root-feeding nematodes can play an important role
Rhizosphere: the root surface as well as the soil directly surrounding plant roots; this is where the most direct plant-soil interactions take place. 


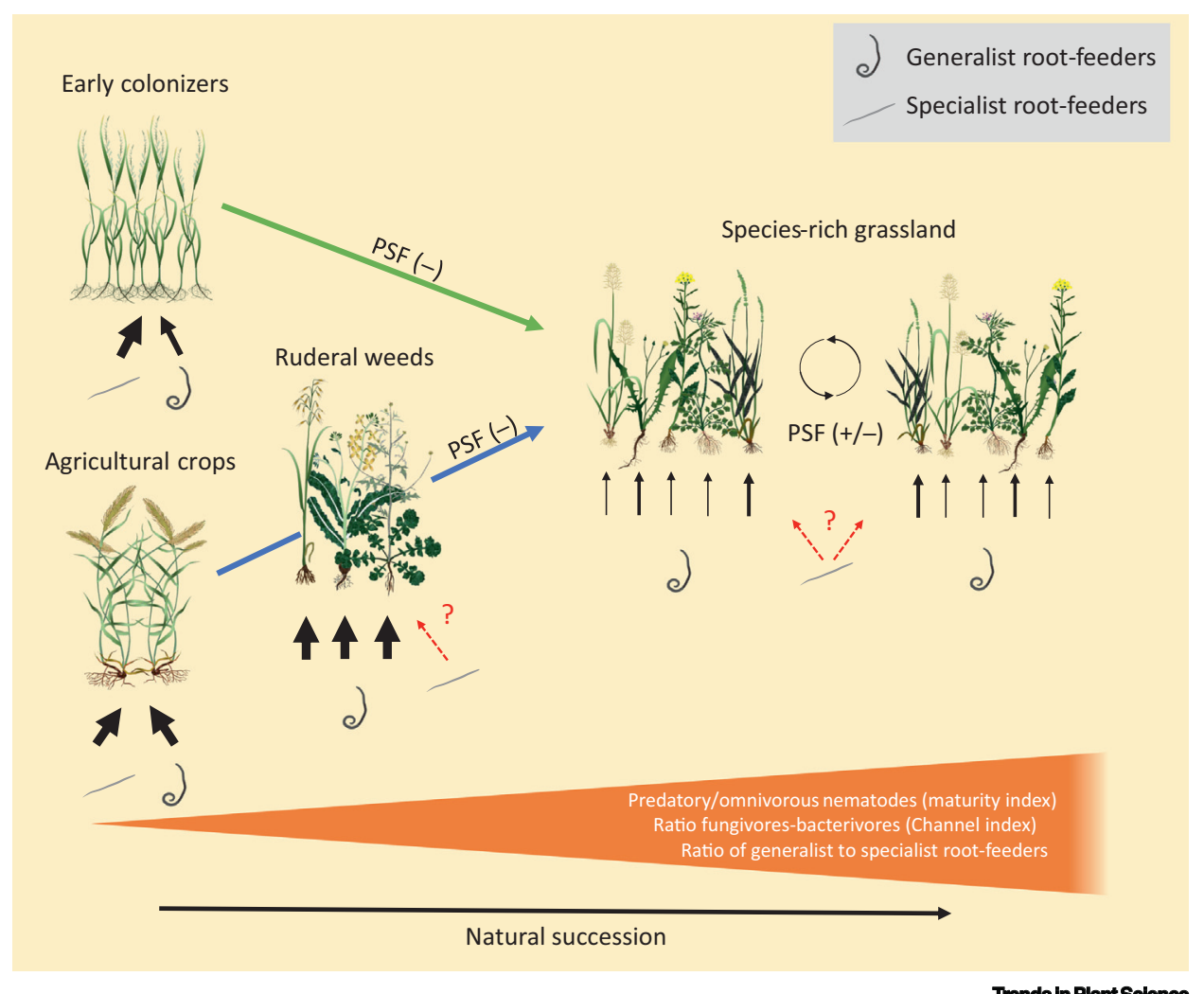

Figure 2. Roles of Soil Nematodes in Plant-Soil Feedbacks and Natural Succession. Under low plant diversity (e.g., stands of coastal dune grasses or crop monocultures), specialist root-feeding nematodes play an important role by strongly contributing to negative plant-soil feedbacks of the dominant plant species (black arrows). In natural systems, this leads to primary succession into species-rich grasslands (green arrow). During secondary succession after abandonment of agricultural fields (blue arrow), communities of ephemeral plants accumulate high numbers of generalist root-feeding nematodes, which contribute to the vegetation turn-over to diverse grassland communities. Plants growing in these communities vary in their defence against generalist root-feeding nematodes, leading to species-specific nematode accumulation and variation in nematode contributions to negative plant-soil feedbacks. In this way, generalist root-feeding nematodes may contribute to spatial turn-over of plant species and vegetation dynamics. The role of specialist rootfeeding nematodes in these species-rich plant communities is not yet understood (red broken arrows with question marks). Along successional gradients, nematode communities show increased maturity as higher trophic-level taxa increase, leading to increased top-down control on lower trophic-level taxa, including root-feeding nematodes. Secondary succession is likely accompanied by a shift from bacterial-feeding to fungal-feeding taxa, indicating a shift in the main decomposition pathway. Abbreviation: PSF, plant-soil feedback.

in natural succession, when they contribute to the dieback of dominant plant species followed by the establishment of non-host plant species [20] (Figure 2).

In species-rich plant communities, root-feeding nematodes with broader host ranges might be of higher functional importance than specialists, which are likely limited by host availability in nearby soil [37]. Yet also generalist root-feeding nematodes may differently affect plant species they attack. First, fast-growing annual species may accumulate higher numbers of generalist rootfeeding nematodes than longer lived plant species, which typically invest more resources in defense [38], possibly explaining the contribution of nematodes to the turnover from ephemeral to more stable grassland communities [22] (Figure 2). Second, inoculation studies show that common generalist root-feeding nematodes, such as Meloidogyne hapla, significantly vary in their multiplication among grassland plant species, even when these are closely related [18,24,26,39]. 
Variation in the accumulation of generalist root-feeding nematodes has recently been shown to correlate to plant-soil feedback variation [18], but this needs further testing. Thus, via speciesspecific accumulation, generalist root-feeding nematodes may, just as specialist root-feeding nematodes, partly underlie species-specific plant-soil feedbacks, and thereby contribute to plant community dynamics [22] (Figure 2).

\section{Indirect Effects of Nematodes on Plant Performance via Interactions with Other Rhizobiome Members}

Many nematodes may not affect plants through direct interactions, but could alter plant performance through indirect interactions with other organisms in the rhizosphere. Root feeders can, in contrast to their negative impacts on plant performance, also benefit plant performance. At low abundances, root feeders can stimulate plant performance indirectly, by inducing increased plant exudation that stimulates microbial activity, leading to enhanced $\mathrm{N}$ and $\mathrm{P}$ availability [40-42]. Other functional groups of nematodes are distributed across the entire soil and rhizosphere food web [43], and structure the rhizobiome, with potential feedbacks to plant performance [14] (Figure 1).

Bacterivores, as the globally most abundant nematodes [6], can reduce bacterial biomass and change bacterial community composition [44-46]. Thereby, they have been shown to increase plant nutrient uptake and plant growth [47,48], although it is not yet known whether all bacterivorous taxa indirectly affect plants in this way. Bacterivores enhance rhizodeposition in the form of easy-available carbon compounds, likely indirectly through preying on bacteria [49]. Overall, up to $20 \%$ of the ingested bacterial $\mathrm{N}$ and $75 \%$ of the $\mathrm{P}$ can be released and made available for plant uptake [50]. Especially together with bacterivorous protists, nematodes increase root branching, which enables higher $\mathrm{N}$ uptake and leads to positive effects on plant performance [50]. This nutrient increase mechanism becomes especially important at low nutrient availability in soils [51], and therefore is likely of profound importance for plant growth in most nutrient-limited natural soils.

Fungivorous nematode numbers are usually at least an order of magnitude lower than numbers of bacterivores, but they nevertheless are major consumers of fungi [43]. They select for their preferred fungal prey and thereby change fungal communities [52]. This, in turn, can enhance plant growth through the stimulation of plant mutualistic mycorrhizal fungi, that increase nutrient transfer to the host plant [53]. Higher trophic-level nematodes (omnivores and predators) are central in food webs, as they prey on nearly all smaller sized organisms including root-feeding nematodes [43,54], thereby likely positively contributing to plant growth $[54,55]$. The protection of plants by entomopathogenic nematodes as parasites of insect larvae is already known from agricultural systems [11], and is likely important for natural plant species that suffer strongly from belowground insect herbivory.

To determine how plants may be affected by indirect impacts of nematode communities, it is crucial to understand the drivers of nematode community structure. Indices summarizing nematode community structure help to link changes in nematode community structure to possible impacts on plant functioning (Box 1). For example, disturbed, nutrient-rich soils (represented by a low maturity index) harbor few higher trophic-level nematodes and many bacterivores [56]. Therefore, ruderal plants that establish in such soils will not benefit from top-down control on root-feeding nematodes (Figure 2). By contrast, late-successional, diverse grassland communities may harbor many predatory nematodes, likely leading to a stronger top-down control on root-feeding nematode communities (Figure 2), and fungivorous nematodes (represented by a high channel index), indicating a shift in decomposition pathway as well as altered impacts on 
Box 2. Biogeography of Soil Nematodes in Natural Soils

In recent years, knowledge on rhizosphere nematodes has profoundly increased, particularly on spatial patterning of nematode community composition. At the global scale, a combination of factors determines nematode abundances and functional group composition in soils, in particular the percentage of soil sand and carbon content, as well as the presence of plants [6]. However, these patterns become less clear at higher taxonomic resolution and smaller spatial scales. Other factors including specific plant species, latitude, and other abiotic factors, can be more important determinants for nematode communities at a continental scale [85]. Nematode communities, including their diversity, are affected by anthropogenic influences with agricultural management, inducing substantial changes in nematode communities compared with those in natural systems $[74,108]$. At the field scale, nematodes have distinct distributions that seem to be largely governed by stochastic processes [109].

Biogeographic differences of nematode communities are more difficult to study at the level of distinct taxonomic groups, as expertise to identify nematode species is limited to a few experts [89]. Sequencing techniques promise to reduce this issue [89], with studies suggesting distinct biogeography of distinct nematode species/OTUs (molecularly defined operational taxonomic units) with many new species likely still to be discovered [36]. Even at the family level it seems that nematodes are not ubiquitously distributed in global soils [110]. Ultimately, there are several knowledge gaps in nematode biogeography in soils, in particular how nematode species distribution is linked to variation in plant-nematode interactions.

the rhizobiome [57]. Plant identity and plant diversity also affect the functional structure of nematode communities, especially at the lower trophic levels [39,57], but more studies are needed to determine general effects. To obtain a broad understanding of how nematode communities affect plant performance across ecosystems, we need to increase our understanding of geographic variation in nematode community structure as well as the biogeographic distribution patterns of specific taxa of (root-feeding) nematodes [36] (Box 2). Together, the changes in plant microbiomes imposed by soil nematodes are likely of functional importance for plant performance, but future research should reveal the relative importance of such indirect plant-nematode interactions compared with the direct impacts of root-feeding nematodes and other soil organismal groups.

\section{Global Change Impacts on Soil Nematode Communities}

Due to the sensitivity of nematode communities to environmental disturbances (Box 1), including changes in temperature and water availability, it may be likely that environmental changes that characterize the Anthropocene affect nematode communities, and alter plant-nematode interactions. Such changes in nematode community composition in response to global change may not only occur directly, but also indirectly (e.g., through changes in plant community composition) [58]. A long-term grassland study recently showed that shifts in nematode communities can last for many years [59], necessitating the need to understand how alterations of the nematode community, in response to global change, feed back to plant performance.

At the local scale, various global change drivers impact nematode communities in natural systems. As nematodes typically inhabit water films in the soil, the increase of droughts associated with climate change will likely affect nematode community structure most directly. Indeed, drought events can diminish or depauperate nematode communities, both directly or via changes in plant community composition [58,60], likely leading to reduced contributions of nematode communities to decomposition [60]. However, a large-scale study along an aridity gradient showed that responses of nematode functional groups to increasing drought may be nonlinear, as fungivores and higher-trophic level nematodes were shown to be more sensitive to increasing drought than bacterivores [61]. Thereby, droughts may structurally alter nematode communities, reflected by changes in key nematode community indices as the maturity index and the channel index (Box 1) [62]. Drought thereby can alter the ratio between predatory and root-feeding nematodes $[60,63]$, leading to reduced top-down control of root feeders, with possible negative effects for plant performance [27] (Figure 1). Similarly, drought may also reduce the top-down control on belowground insect herbivores provided by entomopathogenic nematodes [64] (Figure 1). 
In comparison to drought, effects of elevated temperatures on nematode community structure may be less strong [58]. However, both in subarctic heathland and in diverse temperate grassland, warming increases nematode densities $[65,66]$, whereas such an effect was not found in a desert study [67]. Warming can also structurally affect nematode communities, by decreasing predatory nematodes - and thereby possible top-down control on root-feeding nematodes $[65,68]$, or by decreasing the nematode channel index, indicating a reduction of the relative abundance of fungivorous nematodes [69]. Increases in $\mathrm{CO}_{2}$-concentrations positively affect nematode abundance in grassland soils $[69,70]$, but negatively affect nematode abundance in forest soil [71]. Elevated $\mathrm{CO}_{2}$-concentrations may also lower the maturity index of nematode communities through reductions of long-lived omnivorous and predatory nematodes in grasslands [68], but such an effect has not been found in other studies [58,69,70].

Studies examining the effects of increases in nitrogen pollution and deposition from intensive agriculture show that nitrogen addition can reduce the maturity index of nematode communities, by increasing the dominance of short-lived bacterivorous nematodes [72] or fungivorous nematodes [73], as well as by decreasing numbers of predatory nematodes [73]. At the continental scale, the modification of soils by agricultural practices has led to biotic homogenization of nematode communities across latitudinal gradients [74], a process of which the implications for ecosystem functioning are not yet known.

Overall, most global change factors can alter nematode communities, often by reducing longlived omnivorous and predatory nematode taxa. This may affect belowground food webs and, likely, reduce top-down control on root-feeding nematodes. However, global change effects on nematode communities may be ecosystem specific, emphasizing the need to understand drivers of nematode community composition across ecosystems (Box 2). Moreover, effects of other global change drivers (e.g., plastic pollution) [75] remain largely unexplored. Importantly, global change factors often occur and act in concert, and interactively affect nematode community composition and functioning $[58,69,73]$. How such changes in nematode community structure caused by global change drivers may feed back plant performance is only starting to be explored [27,63], and needs further study.

\section{Plant-Nematode Interactions of Non-native Plant Species}

The establishment of numerous plant species in areas outside their native range, due to intercontinental introductions as well as climate change-driven range expansions, has raised the question of how such non-native plants alter the structure and functioning of soil organisms, including nematodes [76]. Via the introduction of novel litter and root traits, non-native plants may alter belowground food webs [77]. Nematode communities under non-native plant species have been found to be dominated by opportunistic and stress-tolerant taxa $[78,79]$, or to be depauperated in general $[80,81]$, and non-native plant species may cause large-scale biotic homogenization of nematode communities [82]. However, such effects likely depend on nonnative plant identity, as some non-native plants can also positively affect nematode groups typically sensitive to disturbance [83].

Research on plant-nematode interactions of non-native plant species has also focused on the question as to whether decreases in root-feeding nematode diversity and abundance between the original and non-native range of alien plant species contribute to the increased performance of some non-native plants outside their native range (enemy release hypothesis) [84]. Indeed, some non-native plant species accumulate fewer root-feeding nematodes in their non-native range than in their native range, although these effects may be limited to (semi-) endoparasitic taxa and are only found for a couple of plant species $[38,85,86]$. Such reductions of root- 
feeding nematode numbers in the non-native range may be caused by the release from hostspecific taxa [86]. However, the poor performance of generalist root-feeding nematodes on a range-expanding plant species with a divergent root metabolome suggests that non-native plant species may also benefit from the possession of novel defense chemistry in their defense against generalist root-feeding nematodes from the new range [24]. By contrast, root-feeding nematodes can also contribute to biotic resistance against non-native plant species, as these often accumulate comparable root-feeding nematode numbers as native species [18,24,87]. Future research should elucidate whether rapid adaptation of root-feeding nematodes to nonnative plants may contribute to the increasingly negative plant-soil feedbacks that some nonnative plant species experience [88].

\section{Methodological Advances to Improve Understanding of Plant-Nematode Interactions}

To better understand plant-nematode interactions, researchers can base their work on a century-long knowledge of soil nematodes, which has recently been furthered by a range of novel molecular techniques. In particular, we have: (i) well-established techniques to extract and morphologically identify rhizosphere nematodes [89]; (ii) obtained profound insights into the ecological drivers determining nematode abundances and communities in soils [6]; (iii) identified thousands of species [5], and even functionally annotated the majority of those [90]. This information has resulted in a suit of metrices that help to assess soil quality (Box 1), which should now be translated to better understand and predict the direct and indirect impacts of nematode communities on plants. New, user-friendly molecular methods are emerging that help transfer the knowledge obtained by nematode specialists to a broader group of scientists [89]. While these molecular methods still need profound calibration efforts to make them comparable with traditionally used morphology-based techniques [91], they provide unique means to bridge the continuously increasing gap between microbial- and nematode-focused studies [92]. Indeed, data obtained using molecular tools such as high-throughput amplicon sequencing (metabarcoding) provide more valuable information on the composition of nematodes than of microorganisms, as for nematodes individual biomasses can be inferred from sequence data [89,93]. Furthermore, the most commonly performed methods to extract nematodes necessitate nematode movement, and as such only target active taxa, resulting in information that is so far inherently difficult to obtain for other rhizobiome members [94]. The obtained information can directly be used to link the community and abundance of active nematode taxa to the growth of plant species, and thereby provide immediate functional information on the role of nematodes on plant growth. Soil community fractionation experiments [95], in which nematodes can be removed from soil communities, can help us to understand the functional consequences of changes in nematode community composition for plant health (e.g., in response to global change factors). Trophic positions of nematodes, including their effect on the rhizobiome and interactions with plants, can now be derived using stable isotope analysis [96] or pulse labelling plants with ${ }^{14} \mathrm{CO}_{2}$ [97]. Together, these techniques will help us to elucidate the taxonomic and functional diversity of soil nematodes and their role in plant performance.

Other methods still need to be implemented to further enhance the understanding of plantnematode interactions, especially in natural systems. Most promising may be the implementation of whole-genome sequencing, which provides genetic data at the population level and can thus differentiate between distinct nematode pathotypes and a pathogenicity-linked gene repertoire [25]; information that can be translated to understand species-specific interactions between single plant species and nematodes. This will especially help us to understand the occurrence of host specialists in natural root-feeding nematode communities. Moreover, the whole genome sequencing-based approach will enable studies on nematode distribution patterns, which can 
help to link variation in plant performance to spatial variation in nematode community composition at the species level.

A tighter link and knowledge exchange between nematode-centered research fields, as well as between expertise on nematodes from agricultural and natural systems, is of upmost importance to advance insights obtained by future nematode studies. Methodological advances developed based on distinct, well-known agricultural pest species $[98,99]$ should be translated to other nematode species in order to better understand their role in determining plant growth in natural systems. In turn, to identify potential new biocontrol agents, nematode-associated organisms should best be studied in natural systems, as these contain a huge reservoir of nematodeantagonizing organisms including bacteria, fungi, and protists [100,101].

\section{Concluding Remarks}

We have described the versatile role of nematodes in affecting plant performance in natural systems, both directly and indirectly, via interactions with other organisms in the rhizosphere. In many ways, the field of nematode community ecology in natural systems would benefit from the detailed knowledge on nematodes from agricultural systems, in which nematodes are typically studied on the species or pathotype level, as well as from the field of microbial ecology, in which molecular methods are still more advanced. Yet, plant-nematode interactions in natural systems also represent a blueprint for other scientific fields, due to the century long knowledge that integrates taxonomic and functional information. A better integration of nematode-centered research with other soil and rhizobiome fields will further advance our knowledge regarding the plant-soil holobiont [5].

Such an increased understanding of plant-nematode interactions in natural systems is strongly required, as this review shows that nematode communities typically are sensitive to global change. Large-scale experimental network approaches [102], as well as studies including multiple global change factors [69,103], are required in order to obtain a general understanding of how global change affects nematode communities and plant-nematode interactions across ecosystems (see Outstanding Questions).

\section{Acknowledgements}

The authors acknowledge three anonymous reviewers for their constructive comments on a previous version of the manuscript. S. G. was supported by a Veni-grant (016.Veni.181.078) of the Dutch Research Council (NWO).

\section{References}

1. Klein, A.-M. et al. (2007) Importance of pollinators in changing landscapes for world crops. Proc. R. Soc. B Biol. Sci. 274, 303-313

2. van der Heijden, M.G.A. et al. (1998) Mycorrhizal fungal diversity determines plant biodiversity, ecosystem variability and productivity. Nature 396, 69-72

3. Oerke, E.C. (2006) Crop losses to pests. J. Agric. Sci. 144 $31-43$

4. Wardle, D.A. et al. (2004) Ecological linkages between above ground and belowground biota. Science 304, 1629-1633

5. Bardgett, R.D. and van der Putten, W.H. (2014) Belowground biodiversity and ecosystem functioning. Nature 515, 505-511

6. van den Hoogen, J. et al. (2019) Soil nematode abundance and functional group composition at a global scale. Nature 572, 194-198

7. Yeates, G.W. et al. (1993) Feeding-habits in soil nematode families and genera - an outline for soil ecologists. J. Nematol. 25, 315-331

8. Nicol, J.M. et al. (2011) Current nematode threats to world agriculture. In Genomics and Molecular Genetics of PlantNematode Interactions (Jones, J. et al., eds), pp. 21-43, Springer Netherlands
9. Reynolds, L.B. et al. (2000) Crop rotation with Tagetes sp. is an alternative to chemical fumigation for control of root-lesion nematodes. Agron. J. 92, 957-966

10. Timper, P. (2014) Conserving and enhancing biological contro of nematodes. J. Nematol. 46, 75-89

11. Kaya, H.K. and Gaugler, R. (1993) Entomopathogenic nematodes. Annu. Rev. Entomol. 38, 181-206

12. Bakker, P.A.H.M. et al. (2018) The soil-borne legacy. Cell 172 , 1178-1180

13. Rasmann, S. et al. (2005) Recruitment of entomopathogenic nematodes by insect-damaged maize roots. Nature 434, 732-737

14. Thakur, M.P. and Geisen, S. (2019) Trophic regulations of the soil microbiome. Trends Microbiol. 27, 771-780

15. Neher, D. (1999) Soil community composition and ecosystem processes: comparing agricultural ecosystems with natura ecosystems. Agrofor. Syst. 45, 159-185 natural and agricultural soil. In Annual Review of Phytopathology Vol 48) (VanAlfen, N.K. et al., eds), pp. 371-394

17. Wasilewska, L. (1979) The structure and function of soil nematode communities in natural ecosystems and agrocenoses. Pol. Ecol. Stud. 5, 97-145
16. Neher, D.A. (2010) Ecology of plant and free-living nematodes in

\section{Outstanding Questions}

How common is host specialization of root-feeding nematodes, and what is the role of specialist root-feeding nematodes in diverse plant communities?

Do generalist root-feeding nematodes become locally adapted to plant species present in the local community?

Can plants specifically attract and enrich microbial antagonists of rootfeeding nematodes, and if so, which taxa?

What is the relative importance of nonroot-feeding nematodes for plant performance and vegetation dynamics?

How does root-feeding nematode herbivory alter the composition and functioning of rhizosphere microbiomes?

Is there a spill-over of root-feeding nematodes from agricultural systems into natural systems, and what are the consequence for natural vegetation?

How long do global change impacts on nematode communities persist, and how do such community modifications affect plant communities?

How do individual and interactive effects of global change drivers on nematode community functioning vary across ecosystems?

Can root-feeding nematodes be used to provide biotic resistance against non-native plant species?

What are the best techniques to determine keystone nematode species that affect plant performance? 
18. Wilschut, R.A. et al. (2019) Root traits and belowground herbivores relate to plant-soil feedback variation among congeners. Nat. Commun. 10, 1564

19. van Dam, N.M. and Bouwmeester, H.J. (2016) Metabolomics in the rhizosphere: tapping into belowground chemica communication. Trends Plant Sci. 21, 256-265

20. van der Putten, W.H. et al. (1993) Plant-specific soil-borne diseases contribute to succession in foredune vegetation. Nature $362,53-56$

21. van der Putten, W.H. et al. (2013) Plant-soil feedbacks: the past, the present, and future challenges. J. Ecol. 101, 265-276

22. De Deyn, G.B. et al. (2003) Soil invertebrate fauna enhances grassland succession and diversity. Nature 422, 711-713

23. Sikder, M.M. and Vestergård, M. (2020) Impacts of root metabolites on soil nematodes. Front. Plant Sci. 10, 1792

24. Wilschut, R.A. et al. (2017) Belowground plant-herbivore interactions vary among climate-driven range-expanding plan species with different degrees of novel chemistry. Front. Plant Sci. 8, 1861

25. Williamson, V.M. and Kumar, A. (2006) Nematode resistance in plants: the battle underground. Trends Genet. 22, 396-403

26. Brinkman, E. et al. (2015) Plant-feeding nematodes in coastal sand dunes: occurrence, host specificity and effects on plant growth. Plant Soil 397, 17-30

27. Franco, A.L.C. et al. Root herbivory controls the effects of water availability on the partitioning between above- and below-ground grass biomass. Funct. Ecol. Published online August 9, 2020. https://doi.org/10.1111/1365-2435.13661

28. Eisenhauer, N. et al. (2010) Nematicide impacts on nematodes and feedbacks on plant productivity in a plant diversity gradient. Acta Oecol. 36, 477-483

29. Dietrich, P. et al. (2019) Nematode communities, plant nutrient economy and life-cycle characteristics jointly determine plant monoculture performance over 12 years. Oikos Published online December 5, 2019. https://doi.org/10.1111/oik.06989

30. Topalović, O et al. (2020) Plants and associated soil microbiota cooperatively suppress plant-parasitic nematodes. Front. Microbiol. 11, 313

31. Piskiewicz, A.M. et al. (2008) Multiple species-specific controls of root-feeding nematodes in natural soils. Soil Biol. Biochem. 40, 2729-2735

32. Schulz-Bohm, K. et al. (2018) Calling from distance: attraction of soil bacteria by plant root volatiles. ISME J. 12, 1252-1262

33. Vet, L.E.M. and Dicke, M. (1992) Ecology of infochemical use by natural enemies in a tritrophic context. Annu. Rev. Entomol. 37. 141-172

34. Wurst, S. et al. (2009) Plant defence against nematodes is not mediated by changes in the soil microbial community. Funct. Ecol. 23, 488-495

35. Riggs, R.D. et al. (1969) Life cycle, host range, and reproduction of heterodera betulae. J. Nematol. 1, 180-183

36. Ozbayrak, M. et al. (2019) A COI DNA barcoding survey of Pratylenchus species in the Great Plains Region of North America. J. Nematol. 51, 1-21

37. van Der Putten, W.H. (2003) Plant defense belowground and spatiotemporal processes in natural vegetation. Ecology 84 2269-2280

38. Wilschut, R.A. et al. (2018) Nematode community responses to range-expanding and native plant communities in original and new range soils. Ecol. Evol. 8, 10288-10297

39. De Deyn, G.B. et al. (2004) Plant species identity and diversity effects on different trophic levels of nematodes in the soil food web. Oikos 106, 576-586

40. Gebremikael, M.T. et al. (2016) Nematodes enhance plant growth and nutrient uptake under $\mathrm{C}$ and $\mathrm{N}$-rich conditions. Sci. Rep. 6, 32862

41. Bardgett, R.D. et al. (1999) Below-ground herbivory promotes soil nutirent transfer and root growth in grassland. Ecol. Lett. 2 , 357-360

42. Tu, C. et al. (2003) Root-parasitic nematodes enhance soil microbial activities and nitrogen mineralization. Microb. Ecol. 46, 134-144

43. de Ruiter, P.C. et al. (1995) Energetics, patterns of interaction strengths, and stability in real ecosystems. Science 269, $1257-1260$
44. Griffiths, B.S. et al. (1999) Changes in soil microbial community structure in the presence of microbial-feeding nematodes and protozoa. Pedobiologia 43, 297-304

45. Blanc, C. et al. (2006) Nutrition on bacteria by bacterial-feeding nematodes and consequences on the structure of soil bacteria community. Eur. J. Soil Biol. 42, S70-S78

46. Postma-Blaauw, M.B. et al. (2005) Within-trophic group interactions of bacterivorous nematode species and their effects on the bacterial community and nitrogen mineralization. Decologia 142, 428-439

47. Ingham, R.E. et al. (1985) Interactions of Bacteria, Fungi, and their Nematode Grazers: Effects on Nutrient Cycling and Plant Growth. Ecol. Monogr. 55, 119-140

48. Djigal, D. et al. (2004) Influence of bacterial-feeding nematodes (Cephalobidae) on soil microbial communities during maize growth. Soil Biol. Biochem. 36, 323-331

49. Sundin, P. et al. (1990) Interactions between bacteria-feeding nematodes and bacteria in the rape rhizosphere: effects on root exudation and distribution of bacteria. FEMS Microbiol. Lett. 73, 13-22

50. Trap, J. et al. (2016) Ecological importance of soil bacterivores for ecosystem functions. Plant Soil 398, 1-24

51. Biørnlund, L. et al. (2012) Nematodes and protozoa affect plants differently, depending on soil nutrient status. Eur. J. Soil Biol. 50, 28-31

52. John, D. et al. (2000) Food preferences of a fungal-feeding Aphelenchoides species. Nematology 2, 223-230

53. Hua, J. et al. (2014) Interactions between arbuscular mycorrhiza fungi and fungivorous nematodes on the growth and arsenic uptake of tobacco in arsenic-contaminated soils. Appl. Soil Ecol. 84, 176-184

54. Khan, Z. and Kim, Y.H. (2007) A review on the role of predatory soil nematodes in the biological control of plant parasitic nematodes. Appl. Soil Ecol. 35, 370-379

55. Dietrich, P. et al. (2020) Nematode communities, plan nutrient economy and life-cycle characteristics jointly determine plant monoculture performance over 12 years. Oikos 129 , 466-479

56. Ettema, C.H. and Bongers, T. (1993) Characterization of nematode colonization and succession in disturbed soil using the Maturity Index. Biol. Fertil. Soils 16, 79-85

57. Eisenhauer, N. et al. (2011) Changes in plant species richness induce functional shifts in soil nematode communities in experimental grassland. PLOS ONE 6, e24087

58. Kardol, P. et al. (2010) Soil ecosystem functioning unde climate change: plant species and community effects. Ecology 91, 767-781

59. Wubs, E.R.J. et al. (2019) Single introductions of soil biota and plants generate long-term legacies in soil and plant community assembly. Ecol. Lett. 22, 1145-1151

60. Stevnbak, K. et al. (2012) Suppression of soil decomposers and promotion of long-lived, root herbivorous nematodes by climate change. Eur. J. Soil Biol. 52, 1-7

61. Xiong, D. et al. (2019) Nonlinear responses of soil nematode community composition to increasing aridity. Glob. Ecol. Biogeogr. 29, 117-126

62. Yan, D. et al. (2018) Community structure of soil nematodes under different drought conditions. Geoderma 325, 110-116

63. Franco, A.L.C. et al. (2019) Drought suppresses soil predators and promotes root herbivores in mesic, but not in xeric grasslands. Proc. Natl. Acad Sci. 116, 12883-12888

64. Guyer, A. et al. (2018) Influence of drought on plant performance through changes in belowground tritrophic interactions. Ecol. Evol. 8, 6756-6765

65. Thakur, M.P. et al. (2017) Climate warming promotes species diversity, but with greater taxonomic redundancy, in complex environments. Sci. Adv. 3, e1700866

66. Ruess, L. et al. (1999) Simulated climate change affecting microorganisms, nematode density and biodiversity in subarctic soils. Plant Soil 212, 63-73

67. Darby, B.J. et al. (2011) Few apparent short-term effects of elevated soil temperature and increased frequency of summe precipitation on the abundance and taxonomic diversity of desert soil micro- and meso-fauna. Soil Biol. Biochem. 43 , 1474-1481 
68. Mueller, K.E. et al. (2016) Elevated CO2 and warming shift the functional composition of soil nematode communities in a semiarid grassland. Soil Biol. Biochem. 103, 46-51

69. Thakur, M.P. et al. (2019) Soil microbial, nematode, and enzymatic responses to elevated $\mathrm{CO} 2 \mathrm{~N}$ fertilization, warming and reduced precipitation. Soil Biol. Biochem. 135, 184-193

70. Yeates, G.W. et al. (1997) Response of the fauna of a grassland soil to doubling of atmospheric carbon dioxide concentration. Biol. Fertil. Soils 25, 307-315

71. Neher, D. et al. (2004) Elevated CO2 alters functional attributes of nematode communities in forest soils. Funct. Ecol. 18, 584-591

72. Shaw, E.A. et al. (2019) Long-term nitrogen addition shifts the soil nematode community to bacterivore-dominated and reduces its ecological maturity in a subalpine forest. Soil Biol. Biochem. 130, 177-184

73. Eisenhauer, N. et al. (2012) Global change belowground: impacts of elevated $\mathrm{CO} 2$, nitrogen, and summer drought on soil food webs and biodiversity. Glob. Chang. Biol. 18, 435-447

74. Li, X. et al. (2019) Agriculture erases climate constraints on soil nematode communities across large spatial scales. Glob. Chang. Biol. 26, 919-930

75. Mueller, M.-T. et al. (2020) Surface-related toxicity of polystyrene beads to nematodes and the role of food availability. Environ. Sci. Technol. 54, 1790-1798

76. Wolfe, B.E. and Klironomos, J.N. (2005) Breaking new ground: soil communities and exotic plant invasion. Bioscience 55 $477-487$

77. Zhang, P. et al. (2019) Invasive plants differentially affect sol biota through litter and rhizosphere pathways: a metaanalysis. Ecol. Lett. 22, 200-210

78. Peralta, G. et al. (2019) Contrasting responses of soil nematode communities to native and non-native woody plant expansion. Oecologia 190, 891-899

79. Chen, H. et al. (2007) Exotic plant influences soil nematode communities through litter input. Soil Biol. Biochem. 39, 1782-1793

80. Lazzaro, L. et al. (2018) How ecosystems change following invasion by Robinia pseudoacacia: Insights from soil chemica properties and soil microbial, nematode, microarthropod, and plant communities. Sci. Total Environ. 622, 1509-1518

81. Belnap, J. et al. (2005) Soil biota can change after exotic plant invasion: does this affect ecosystem processes? Ecology 86, 3007-3017

82. Zhang, Y. et al. (2019) Biotic homogenization of wetland nematode communities by exotic Spartina alterniflora in China Ecology 100, e02596

83. Peltzer, D.A. et al. (2009) Punching above their weight: lowbiomass non-native plant species alter soil properties during primary succession. Oikos 118, 1001-1014

84. Keane, R.M. and Crawley, M.J. (2002) Exotic plant invasions and the enemy release hypothesis. Trends Ecol. Evol. 17 , 164-170

85. Wilschut, R.A. et al. (2019) Latitudinal variation in soil nematode communities under climate warming-related range-expanding and native plants. Glob. Chang. Biol. 25, 2714-2726

86. van der Putten, W.H. et al. (2005) Invasive plants and their escape from root herbivory: a worldwide comparison of the root-feeding nematode communities of the dune grass Ammophila arenaria in natural and introduced ranges. Biol. Invasions 7, 733-746

87. Jurová, J. et al. (2019) Effects of the invasive common milkweed (Asclepias syriaca) on nematode communities in natural grasslands. Nematology 1, 1-16

88. Diez, J.M. et al. (2010) Negative soil feedbacks accumulate over time for non-native plant species. Ecol. Lett. 13, 803-809
89. Geisen, S. et al. (2018) Integrating quantitative morphological and qualitative molecular methods to analyse soil nematode community responses to plant range expansion. Methods Ecol. Evol. 9, 1366-1378

90. Yeates, G. et al. (1993) Feeding habits in soil nematode families and genera-an outline for soil ecologists. J. Nematol. 25 , 315-331

91. Griffiths, B.S. et al. (2018) The need for standardisation: exemplified by a description of the diversity, community structure and ecological indices of soil nematodes. Ecol. Indic. 87, 43-46

92. Geisen, S. et al. (2017) Soil protistology rebooted: 30 fundamental questions to start with. Soil Biol. Biochem. 111, 94-103

93. Schenk, J. et al. (2019) Metabarcoding data allow for reliable biomass estimates in the most abundant animals on earth Metabarcoding Metagenomics 3, 117-126

94. Blagodatskaya, E. and Kuzyakov, Y. (2013) Active microorganisms in soil: critical review of estimation criteria and approaches. Soil Biol. Biochem. 67, 192-211

95. Wang. M. et al. (2019) Removal of soil biota alters soil feedback effects on plant growth and defense chemistry. New Phytol. 221, 1478-1491

96. Melody, C. et al. (2016) Stable isotope analysis ( $813 \mathrm{C}$ and $\delta 15 N$ ) of soil nematodes from four feeding groups. PeerJ 4 , $\mathrm{e} 2372$

97. Pausch, J, et al. (2016) Fluxes of root-derived carbon into the nematode micro-food web of an arable soil. Food Webs 9 , 32-38

98. Toyota, K. et al. (2008) Development of a real-time PCR method for the potato-cyst nematode Globodera rostochiensis and the root-knot nematode Meloidogyne incognita. Soil Sci. Plant Nutr. 54, 72-76

99. Min, Y.Y. et al. (2012) A novel nematode diagnostic method using the direct quantification of major plant-parasitic nematodes in soil by real-time. PCR 14, 265-276

100. Geisen, S. et al. (2015) Pack hunting by a common soil amoeba on nematodes. Environ. Microbiol. 17, 4538-4546

101. Gray, N.F. (1987) Nematophagous fungi with particular reference to their ecology. Biol. Rev. 62, 245-304

102. Leff, J.W. et al. (2015) Consistent responses of soil microbia communities to elevated nutrient inputs in grasslands across the globe. Proc. Natl. Acad. Sci. 112, 10967-10972

103. Kardol, P. et al. (2010) Climate change effects on plant biomass alter dominance patterns and community evenness in an experimental old-field ecosystem. Glob. Chang. Biol. 16 2676-2687

104. Bongers, T. and Ferris, H. (1999) Nematode community structure as a bioindicator in environmental monitoring. Trends Ecol. Evol. 14, 224-228

105. Bongers, T (1990) The maturity index: an ecological measure of environmental disturbance based on nematode species composition. Oecologia 83, 14-19

106. Ferris, H. et al. (2001) A framework for soil food web diagnostics: extension of the nematode faunal analysis concept. Appl. Soil Ecol. 18, 13-29

107. Yeates, G.W. (2003) Nematodes as soil indicators: functiona and biodiversity aspects. Biol. Fertil. Soils 37, 199-210

108. Bongiorno, G. et al. (2019) Reduced tillage, but not organic matter input, increased nematode diversity and food web stability in European long-term field experiments. Mol. Ecol. $28,4987-5005$

109. Quist, C.W. et al. (2019) Spatial distribution of soil nematodes relates to soil organic matter and life strategy. Soil Biol. Biochem. 136, 107542

110. Nielsen, U.N. et al. (2014) Global-scale patterns of assemblage structure of soil nematodes in relation to climate and ecosystem properties. Glob. Ecol. Biogeogr. 23, 968-978 